\title{
A drop in the ocean
}

\author{
Wave power and other renewable-energy resources deserve carefully targeted government support.
}

$$
\text { ti }
$$
$\mathrm{f}$ the world is to wean itself off fossil fuels, a wide range of alternative energy sources will have to be brought into play. The geographically dispersed nature of renewable resources, including power from solar, wind, wave, tidal and geothermal sources, underscores the need for different nations to develop viable alternatives that utilize the resources they are best placed to exploit.

But some technologies are struggling to make their mark. The harnessing of wave power, for example, has so far had mixed results. This renewable resource held considerable currency in some territories during earlier energy crises, but it has yet to make any real contribution to the global energy mix (see page 156). After the energy "Wave power has
been relegated to
a 'second tier' of
renewable-energy
resources." crises of 1974 and 1979, nations in the stormy northern Atlantic Ocean, including Britain and Norway, set up relatively modest programmes to explore wave power. But faced with assessments suggesting that the costs of wave power were unlikely to fall quickly enough to render it competitive, government backing for wave energy was all but abandoned.

Now the energy crisis is back with a bang, and numerous privately run companies around the world are testing wave-power devices, many of them developed in collaboration with university researchers. All of the designs face common obstacles. They will need to survive in a physically hostile and corrosive environment, which will sometimes subject them to forces ten or twenty times as great as those they need for normal operation. And although economies of scale will reduce the costs of wave-power plants, such reductions are likely to follow the unspectacular trajectories enjoyed by, say, builders of marine engines, rather than the spectacular leaps achieved by manufacturers of silicon chips.

These are the considerations that have, in effect, relegated wave power to a 'second tier' of renewable-energy resources that do not attract substantial public- or private-sector backing. Yet there is a strong argument, given the grim outlook for the world's energy supply, that such support should be forthcoming so that the commercial viability of

\section{The great divide}

\section{The gap between theory and practice remains surprisingly wide in conservation biology.}

M en and women do not decide to become conservation biologists because they yearn for riches and fame, for swimming pools or caviar. They decide to become conservation biologists because they want to stop species from becoming extinct.

So it can sometimes come as a surprise for outsiders to learn how far removed the conservation biologist often is from actual efforts to save species. Most of the time, conservation biologists describe the more promising wave technologies can be examined more fully.

The London-based Carbon Trust, a company set up by the UK government to promote a low-carbon economy, has identified wave energy as one of Britain's most promising renewable resources, with the potential to provide up to 20 gigawatts of power by 2050 . But the trust estimates that it could cost $£ 2.2$ billion (US $\$ 4.6$ billion) in development to reduce the cost of wave-generated electricity from current estimates of between $12 p$ and $44 \mathrm{p}$ to a competitive $6 \mathrm{p}$ per kilowatt-hour.

That sum may seem daunting to the British government acting on its own; but in global terms, it isn't much. The Carbon Trust estimates, for example, that Denmark has so far spent $£ 1.3$ billion on the development of wind power. The Japanese government has invested at least $£ 1$ billion in solar power. And don't mention it to the nuclear lobby, but the amount of public money invested to make atomic power fit-for-purpose was orders of magnitude higher.

Both governments and private investors, of course, need assurance that any wave-power technologies they decide to support will have some worth. To gauge the potential of different designs, it can be valuable for backers of rival technologies to benchmark prototype equipment and compare it objectively with the competition.

A promising model in this regard is the European Marine Energy Centre in the Orkney Islands in Scotland, a testing site set up in 2003 that receives support from Edinburgh, London and Brussels. The centre helps private companies to test their wave-power designs. One firm, Edinburgh-based Pelamis, has already tested and improved its design at the centre, and four more are expected to do so in the next two years.

Such benchmarking can, of course, get wave energy only so far. At some stage, it will have to take its chances on the open market. But in the meantime, governments whose coastlines may be suitable for wave energy should support promising technologies to an extent that will at least allow for a firmer measure of their viability.

problems, float solutions, prioritize areas and actions, and run computer models of natural ecosystems. They are cartographers of crises, producing demoralizing maps of threat and extinction. They are adept at coming up with ever-better methods of doing more with less - at least in theory (see page 152).

It generally falls to a separate and amorphous group, known as 'practitioners', to buy land, put up fences, set fires, put out fires, lobby politicians, negotiate with farmers, spray invasive weeds, poison rats and guard against poachers. These people are generally not conservation biologists: they are civil servants, environmental consultants, park managers or environmental lobbyists.

The distance between these two groups creates a sometimes-yawning 'implementation gap' between theory and practice. Conservation 